28 G. Srinivas, J. Wright, C.-S. Bai and R. Cook, Stud.Surf. Sci. Catal., 1996, 101, 427

29 R.W. Joyner, F. King, M.A. Thomas and G. Roberts, Catal. Today, 1991, 10, 417

30 A.A. Mirzai, M.R.H. Siddiqui, S.H. Taylor, C.J. Kieley, A. Burrows, R.W. Joyner and G.J. Hutchings, in preparation

31 G.J. Hutchings, M.R.H. Siddiqui, A. Burrows, C.J. Kiely and R. Whyman, J. Chem. Soc., Faraday Trans., in press

32 F. Boccuzzi, A. Chiorino, S. Tsubota and M. Haruta, Catal. Lett., 1994, 29, 225

33 H. Sakurai, S. Tsubota and M. Haruta, Appl. Catal., 1993, 102, 125
34 H. Sakurai and M. Haruta, Catal. Today, 1996, 29, 361

35 M. Haruta, A.Ueda, S. Tsubota and R.M. Torres Sanchez, Catal. Today, 1996, 29, 443

36 T. Kobayashi, M. Haruta, S. Tsubota and H. Sano, Sensors. Act., 1987, B1, 222

37 M. Ando, T. Kobayashi and M. Haruta, 5th Int. Meet. Chem. Sensors, 1994, 1156

38 F. Boccuzzi, A. Chiorino, S. Tsubota and M. Haruta, Sensors. Act., 1995, B24-25, 540

39 A. Ueda, T. Oshima and M. Haruta, Environ. Catal., 1995, 343

\title{
Spacing Nanoparticles of Gold Using DNA
}

Nanotechnology has potential applications in electronics, computing, sensors and catalysis $(1,2)$ and is exciting public interest (3). Good progress has been made on devising methods for controlling the chemical composition, size and dispensability of colloidal particles, and methods are now being developed for assembling them into useful aggregates and materials. Following work at Liverpool University, UK on the preparation of thiol-derivatized gold nanoparticles (1), two papers published in the same issue of Nature $(3,4)$ from the University of California, Berkeley, and North-Western University, Illinois, in the USA indicate how molecules of DNA capped with thiol can be used to control the spacing between gold particles.

Alivisatos et al (4) point out that patterning matter on the nanometre scale is an important step towards further miniaturizing electronic components. At the nanometre scale materials properties are strongly size-dependent and can be sensitively tuned. A strategy is described for the synthesis of 'nanocrystal molecules' in which discrete numbers of gold nanocrystals are organized into spatially-defined structures based on Watson-Crick base-pairing interactions. Single stranded DNA oligonucleotides of defined length and sequence are attached to individual nanocrystals, and these assemble into dimers and trimers on addition of a complementary single-stranded DNA template. The extension of this approach to the construction of more complex two and three dimensional assemblies is forecast.
The method described by Mirkin et al (5) involves attaching to the surface of two batches of $13 \mathrm{~nm}$ gold particles, non-complementary DNA oligonucleotides capped with thiol groups, which bind to gold (1). On addition of a solution of an oligonucleotide duplex with 'sticky ends' that are complementary to the two grafted sequences, the nanoparticles self assemble into aggregates. It is forecast that use of the specificity of DNA interactions to direct the interactions between particles of different size and composition could make it possible to tailor the optical, electronic and structural properties of the colloidal aggregates. The colloidal particles of gold have large extinction coefficients for the bands which give rise to their colours; and these intense colours, e.g. the so-called 'Purple of Cassius', which depend on particle size, concentration and interparticle distance, suggest that they will find use in new colorimetric sensing and sequencing strategies for DNA.

\section{David Thompson}

\section{REFERENCES}

1 R. Whyman, Gold Bull., 1996, 29, 11

2 G.M. Francis and R.E. Palmer, Gold Bull, $1996,29,47$

3 C. Jones, Financial Times, 15 August 1996

4 A.P. Alivisatos, K.P. Johnson, X. Peng, T.E. Wilson, C.J. Loweth, M.P. Bruchez and P.G. Schultz, Nature, 1996, 382, 607

5 C.A. Mirkin, R.L. Letsinger, R.C. Mucic and J.J. Storhoff, Nature, 1996, 382, 607 